family Cichlidae. As most of the 40 or so lakes have been isolated from each other for millions of years, new species of fish have evolved which are endemic to certain lakes. I have seen reports that Lake Barombi Mbo (or Lake Kumba) contains 11 endemic cichlids ${ }^{1-3}$ and one endemic Clarias ${ }^{1}$, Lake Barombi Kotto and Lake Mboandong five cichlids including two endemic forms (one species and one subspecies) ${ }^{3-5}$, Lake Ejagham two (possibly three) endemic cichlid species (ref. 6 and E. Trewavas, personal communication) and Lake Bemin one endemic cichlid ${ }^{\text {? }}$.

The important question is: what has happened to any fish that were living in Lake Nyos? If they did not survive the event, we would be comforted by the information that events of this magnitude occur very rarely in the western Cameroon volcanic lakes and have not happened at Lake Nyos for perhaps millions of years. On the other hand, if Lake Nyos is atypical and had no cichlids before the disaster it might be a sign that such events had occurred before and killed the fish. It would then be worth investigating if similar events in the past, particularly those associated with "legends of the Lake Monoun area, [where] there may have been at least three earlier cases of exploding lakes or mass death". There are reports that Lake Monoun had a population of fishes that were killed by the 1984 event, but it is believed that the fishes had never been recorded scientifically (E. Trewavas, personal communication).

If the fish population of Lake Nyos has not been seriously affected by the event, the tolerance levels of the fish for various physical and chemical impacts might be helpful in deciding which of the various scenarios postulated for the event could in fact have occurred.

A similar situation might exist for the distributions of other vertebrate and invertebrate species, which could provide additional data of importance to the examination of previous events and the prediction of future ones. I would be pleased to know if anyone has followed or is following this line of investigation and, if so, what results have been obtained.

WALTER SHEARER

The United Nations University,

Toho Seimei Building,

15-1 Shibuya 2-chome,

Shibuya-ku, Tokyo 150, Japan

1. Trewavas, E., Green, J \& Corbet, S.A. J. Zool., Lond. 167, 41-95 (1972).

2. Trewavas, E. Tilapiine Fishes of the Genera Sarotherodon, Oreochromis and Danakilia (British Museum, London, 1983).

3. Trewavas,E. Bonn. zool. Beitr., 146-192 (1962)

4. Fryer, G. \& Iles, T.D. The Cichlid Fishes of the Great Lakes of Africa: Their Biology and Evolution (Oliver and Boyd, Edinburgh, 1972)

5. Trewavas, E. Bull. Brit. Mus. Nat. Hist. (Zool.) 26, 329-419 (1974).

6. Thys van den Audenaerde, D.F.E. Rev. Zool. Bot. Afr.76, 349-356 (1967).

7. Thys van den Audenaerde, D.F.E. Rev. Zool. Bot. Afr. $\mathbf{8 5}$, 93-98 (1972).

8. Kerr, R.A. Science 235, 528-529 (1987)

\section{Shrödinger's grand theme shortchanged}

SIR-Perutz's ${ }^{1}$ critical review of Schrödinger's What is Life ? $^{2}$ focused only on the leaves and not only missed the forest but the trees as well. His review sifted through reductionist references of the past and dismissed the important themes developed by Schrödinger, who noted that living systems displayed two fundamental processes. One he called "order from order", and the other "order from disorder". Schrödinger synthesized and characterized the existing physical knowledge of the soon to be discovered DNA with the former and then proceeded to integrate the laws of thermodynamics with biology with the latter.

Perutz is correct in recognizing the influence of the earlier Timoféeff, Zimmer, and Delbruck paper ${ }^{3}$ on Schrödinger's determination of the possible size and stability of genetic material. But Schrödinger, as a physicist, should not be faulted for failing to have followed all the obscure literature in genetic and molecular biology being written at the time. His view of the genome, as an aperiodic crystal with unusual stability and coding capabilities was demonstrated later by Watson and Crick's analysis of ribonucleic acids and provided a framework that has led to some of the most important findings in biology today.

Schrödinger's most important and least studied observation was his "order from disorder" premise which links all biological systems with the expanded fundamental theorems of thermodynamics. $\mathrm{He}$ noted that, at first glance, living systems seem to defy the second law of thermodynamics. The law insists that, within closed systems, entropy should be maximized and disorder should reign at equilibrium. Living systems, however, are the antithesis of disorder as they display marvellous levels of order made from disorder. Schrödinger solved this dilemma by turning to 'non-equilibrium thermodynamics', recognizing that living systems live in a world of energy flux and that an organism stays alive in its highly organized state by taking energy from outside itself, or from a larger encompassing system, and processes it to produce a lower entropy state within itself. Life is a farfrom-equilibrium dissipative structure that maintains its local level of organization, or negentropy, at the expense of the large global entropy budget.

Prigogine ${ }^{4}$ and Morowitz ${ }^{5}$ have extended thermodynamics into the realm predicted by Schrödinger, and new advances are rapidly being made in biology that are firmly rooted in this new thermodynamic paradigm $^{6}$. All living systems appear as quasi-stable, far-from-equilibrium dissipative structures. These systems evolve via bifurcations and autocatalytic non- linear processes, and the development of entropy production, growth, complexity and cycling and thermodynamically constrained biology may soon add new dimensions to physics (and thermodynamics in particular), as Schrödinger suggested it might.

Schrödinger was influenced by the Boltzman school and both mens' work was based on statistical interpretations of Nature. Schrödinger's genius lies in the way he was able to describe the important microscopic features of life within the confines of quantum mechanics and statistical thermodynamics. Perutz contends that Schrödinger's essay was not original work, and its chief merit was the popularization of the Timoféeff paper. I am sorry that Perutz missed Schrödinger's grand theme of the possible description of biologic processes within the framework of modern physics.

ERIC D. SCHNEIDER Chesapeake Biological Laboratory,

University of Maryland,

Solomons, Maryland 20688, USA

Perutz, P.M. Nature 326, 555-558 (1987).

. Schrödinger, E. What is Life? (Cambridge University Press, London, 1946).

3. Timoféeff-Ressovsky, N.W., Zimmer, K.G. \& Delbruck M. Nachrichten aus der Biologie der Gesellschaft der Wissenschaften Göttingen 1, 189-245 (1935).

4. Prigogine, I. Introduction to Thermodynamics of Irreversible Processes (Wiley, New York, 1955)

Morowitz, H. Energy Flow in Biology (Academic, New York, 1968).

6. Ulanowicz, R. Growth and Development: Ecosystems Phenomenology (Springer, New York, 1986)

\section{Chain flexilibity and antigenicity}

SIR-I bring your attention to a misconception about antigen-antibody interactions that continues to be propagated in the literature, most recently in an article in Nature $(\mathbf{3 2 6}, 358-363 ; 1987)$. There has never been evidence that "the antigenic regions of proteins are located in the more flexible chain segments". Rather, from limited data, it was suggested that continuous epitopes correspond to flexible regions (Nature 311, 123-126; 1984). Even if this interpretation is correct, it is not known whether discontinuous epitopes, which probably make up the bulk of the antigenic regions on a protein, would also be found in the flexible regions. Moreover, further analysis of the antigenic sites on the tobacco mosaic virus protein (the key protein examined in correlating flexibility with continuous epitopes) has shown that the entire polypeptide chain is antigenic (EMBO J. 4, 1231-1235; 1985). It is, therefore, unlikely that polypeptide chain flexibility plays a major role in antigenicity if it has anything at all to do with it.

RONALD JEMMERSON

Department of Microbiology,

University of Minnesota,

Minneapolis,

Minnesota 55455, USA 